\title{
Análise de crescimento e produtividade de cultivares de arroz de terras altas dos tipos tradicional, intermediário e moderno ${ }^{1}$
}

\author{
Rita de Cassia Felix Alvarez ${ }^{2}$, Carlos Alexandre Costa $\mathrm{Crusciol}^{3}$, Adriano Stephan Nascente ${ }^{4}$
}

\begin{abstract}
Growth analysis and yield of traditional, intermediate and modern upland rice cultivars

The growth analysis allows the characterization and understanding of the upland rice cultivars development. This study aimed at characterizing, by using the growth analysis, the physiological components and agronomic performance, as well as the differences among traditional, intermediate and modern upland rice cultivars. The experiment was conducted under upland rice conditions, favored by the use of supplementary irrigation. The experimental design was randomized blocks, with three treatments consisting of traditional (Caiapó), modern (Maravilha) and intermediate (BRS Primavera) cultivars and eight replications. The leaf area index (LAI), instantaneous growth rate (IGR), relative growth rate (RGR), net assimilation rate (NAR) and specific leaf area (SLA), as well as grain yield and yield components, were evaluated. The intermediate and traditional cultivars presented the highest total dry matter accumulation rate, while the traditional and modern ones showed the highest LAI. The intermediate cultivar presented the highest IGR, RGR, NAR and SLA levels, as well as the highest grain yield, as a consequence of the higher spikelet fertility and 1,000 grain mass.
\end{abstract}

KEY-WORDS: Oryza sativa L.; plant development; leaf area index; plant physiological components.

\section{INTRODUÇÃO}

O arroz (Oryza sativa L.) é um dos cereais mais cultivados no mundo, com produção de 696 milhões de toneladas, na safra 2009/2010, e produtividade de $4.368 \mathrm{~kg} \mathrm{ha}^{-1}$ (FAO 2012), tendo grande importância social e econômica para a população brasileira (Santos et al. 2006, Heinemann \& Stone 2009, Guimarães et al. 2011, Menezes et al. 2011, Nascente et al. 2011).

\section{RESUMO}

A utilização da técnica de análise de crescimento permite caracterizar e entender o comportamento diferenciado de cultivares de arroz de terras altas. Este trabalho objetivou caracterizar, por meio da análise de crescimento, os componentes fisiológicos e o desempenho agronômico, bem como as diferenças existentes entre cultivares de arroz de terras altas do tipo tradicional, intermediário e moderno. $\mathrm{O}$ experimento foi conduzido em condições de terras altas, favorecidas pelo uso de irrigação suplementar. $\mathrm{O}$ delineamento experimental utilizado foi em blocos ao acaso, com três tratamentos constituídos por cultivares do tipo tradicional (Caiapó), moderno (Maravilha) e intermediário (BRS Primavera) e oito repetições. Foram estimados o índice de área foliar (IAF), taxa de crescimento da cultura (TCC), taxa de crescimento relativo (TCR), taxa assimilatória líquida ou aparente (TAL) e área foliar específica (AFE), além da produtividade de grãos e componentes de produção. As cultivares dos grupos intermediário e tradicional apresentaram os maiores acúmulos de matéria seca total e as dos grupos tradicional e moderno os maiores IAFs. A cultivar do grupo intermediário apresentou os maiores índices de TCC, TCR, TAL e AFE, bem como a maior produtividade de grãos, em decorrência dos maiores valores de fertilidade das espiguetas e massa de 1.000 grãos.

PALAVRAS-CHAVE: Oryza sativa L.; desenvolvimento vegetal; índice de área foliar; componentes fisiológicos da planta.

No Brasil, a área cultivada, na safra 2011/2012, foi de 2,45 milhões de hectares, sendo que a cultura ocupou cerca de $65 \%$, em terras altas. Entretanto, a produtividade ainda é baixa $\left(3.200 \mathrm{~kg} \mathrm{ha}^{-1}\right)$ e, consequentemente, este sistema representa apenas $41 \%$ da produção nacional (Conab 2012).

A análise de crescimento é uma técnica que detalha as mudanças morfofisiologicas da planta, em função do tempo, avaliando, também, a produção

1. Trabalho recebido em abr./2012 e aceito para publicação em nov./2012 (nºgistro: PAT 18228).

2. Universidade Federal de Mato Grosso do Sul (UFMS), Faculdade de Agronomia, Chapadão do Sul, MS, Brasil.

E-mail: rita.alvarez@ufms.br.

3. Universidade Estadual Paulista (Unesp), Faculdade de Ciências Agronômicas, Departamento de Produção e Melhoramento

Vegetal, Botucatu, SP, Brasil.E-mail:crusciol@fca.unesp.br.

4. Embrapa Arroz e Feijão, Santo Antônio de Goiás, GO, Brasil.E-mail: adriano.nascente@embrapa.br. 
fotossintética, por meio do acúmulo de matéria seca (Falqueto et al. 2009, Concenço et al. 2011). Esta análise representa informação básica da produção da cultura e pode ser obtida sem a necessidade de equipamentos sofisticados (Falqueto et al. 2009). Para isto, são realizadas avaliações periódicas da quantidade de fitomassa produzida pela planta e suas estruturas (folhas, caules, flores e grãos) e do tamanho da unidade fotossintetizadora (área foliar), durante o desenvolvimento da planta (Benincasa 2003, Taiz \& Zeiger 2009), tornando possível, assim, avaliar o crescimento final da planta, bem como a contribuição de cada órgão no seu desenvolvimento total (Campos et al. 2008).

Dessa forma, verifica-se que a análise de crescimento pode ser utilizada nas observações das variáveis fisiológicas que se correlacionam positivamente com a produtividade de grãos (Santos \& Costa 1997, Campos et al. 2008), e as informações resultantes podem ser utilizadas para verificar a adaptação da cultura a novos ambientes, competição interespecífica e efeitos de sistemas de manejo, além do potencial produtivo de diferentes cultivares (Antoniazzi \& Deschamps 2006, Falqueto et al. 2009).

Diversas variáveis fisiológicas são utilizadas com o objetivo de explicar e entender as diferenças de comportamento das espécies vegetais. A mais utilizada é o índice de área foliar (IAF), que mensura a intensidade de competição por luz entre plantas individuais, dentro de uma população (Taiz \& Zeiger 2009).

A produtividade variável de grãos entre cultivares de arroz ocorre devido a diferenças de redistribuição de assimilados entre os órgãos, durante o crescimento e desenvolvimento das plantas, sendo que a produção de matéria seca e a translocação de fotoassimilados, na ausência de estresses bióticos e abióticos, proporcionam aumento na produtividade da cultura, quando se comparam cultivares pertencentes a um mesmo grupo (Stone \& Steinmetz 1979, Santos \& Costa 1997, Kato et al. 2004, Costa et al. 2008, Falqueto et al. 2009, Heinemann \& Stone 2009, Concenço et al. 2011, Guimarães et al. 2011).

De maneira geral, as cultivares do tipo tradicional são caracterizadas por apresentarem porte alto, com folhas longas e decumbentes e grãos longos e vítreos; baixa capacidade de perfilhamento; boa resistência a doenças de importância secundária; maior estabilidade produtiva, em relação às do tipo moderno, em condições adversas; e acamamento em solos férteis, quando adubadas com doses elevadas de nitrogênio, bem como quando recebem maior aporte tecnológico no sistema de produção.

As cultivares do tipo moderno caracterizam-se como plantas de porte baixo, com grãos, geralmente, longos e finos, folhas curtas e eretas, colmos fortes e elevado perfilhamento, que respondem, em produtividade de grãos, a altos níveis tecnológicos, como adubação, sem resultar em acamamento.

Já as cultivares do tipo intermediário, normalmente, resultam do cruzamento de cultivares do tipo tradicional e moderno, objetivando a redução do porte da planta e a melhoria da qualidade do grão, exigindo, teoricamente, nível tecnológico intermediário, com relação a ambos os grupos precursores (Pinheiro et al. 1985, Santos et al. 2006).

Assim, partindo-se da hipótese de que a utilização da técnica de análise de crescimento permite caracterizar e entender o comportamento diferenciado de cultivares de arroz de terras altas do tipo tradicional, intermediário e moderno, este trabalho objetivou caracterizar, por meio da análise de crescimento, seus componentes fisiológicos e desempenho agronômico.

\section{MATERIAL E MÉTODOS}

O experimento foi conduzido em condições de terras altas, favorecidas pelo uso de irrigação suplementar por aspersão, no ano agrícola de 2005/2006, em Botucatu (SP) $\left(48^{\circ} 26^{\prime} \mathrm{W}, 22^{\circ} 51^{\prime} \mathrm{S}\right.$ e altitude de 740 m). O clima, conforme a classificação de Köppen, é do tipo Cwa, caracterizado como tropical de altitude, com inverno seco e verão quente e chuvoso. Adicionalmente, foram avaliadas, diariamente, as temperaturas máxima, mínima e média, além da precipitação pluvial (Figura 1).

O solo da área experimental foi classificado como Nitossolo Vermelho estruturado (Embrapa 2006). Seus atributos químicos foram determinados (Raij et al. 1996) antes da instalação do experimento, na camada $0,0-0,20 \mathrm{~m}$, apresentando os seguintes valores: $\mathrm{pH}\left(\mathrm{CaCl}_{2}\right)=4,5 ; \mathrm{MO}=22 \mathrm{~g} \mathrm{~kg}^{-1} ; \mathrm{P}($ resina $)=$ $4,0 \mathrm{mg} \mathrm{dm}^{-3} ; \mathrm{K}=0,44 \mathrm{cmol}_{\mathrm{c}} \mathrm{dm}^{-3} ; \mathrm{Ca}=1,2 \mathrm{cmol}_{\mathrm{c}} \mathrm{dm}^{-3}$; $\mathrm{Mg}=0,8 \mathrm{cmol}_{\mathrm{c}} \mathrm{dm}^{-3} ; \mathrm{H}+\stackrel{\mathrm{c}}{\mathrm{Al}}=6,4 \mathrm{cmol}_{\mathrm{c}} \mathrm{dm}^{-3} ; \mathrm{C}_{\mathrm{C} C}=$ $8,8 \mathrm{cmol}_{\mathrm{c}} \mathrm{dm}^{-3}$; e saturação por bases $(\mathrm{V})=27 \%$.

$\mathrm{O}$ delineamento experimental utilizado foi em blocos ao acaso, com oito repetições. Os tratamentos foram compostos pelas cultivares Caiapó, BRS Primavera e Maravilha. A escolha destas cultivares se deu em função do tipo de planta (arquitetura e porte), sendo a primeira do grupo tradicional, a segunda do 


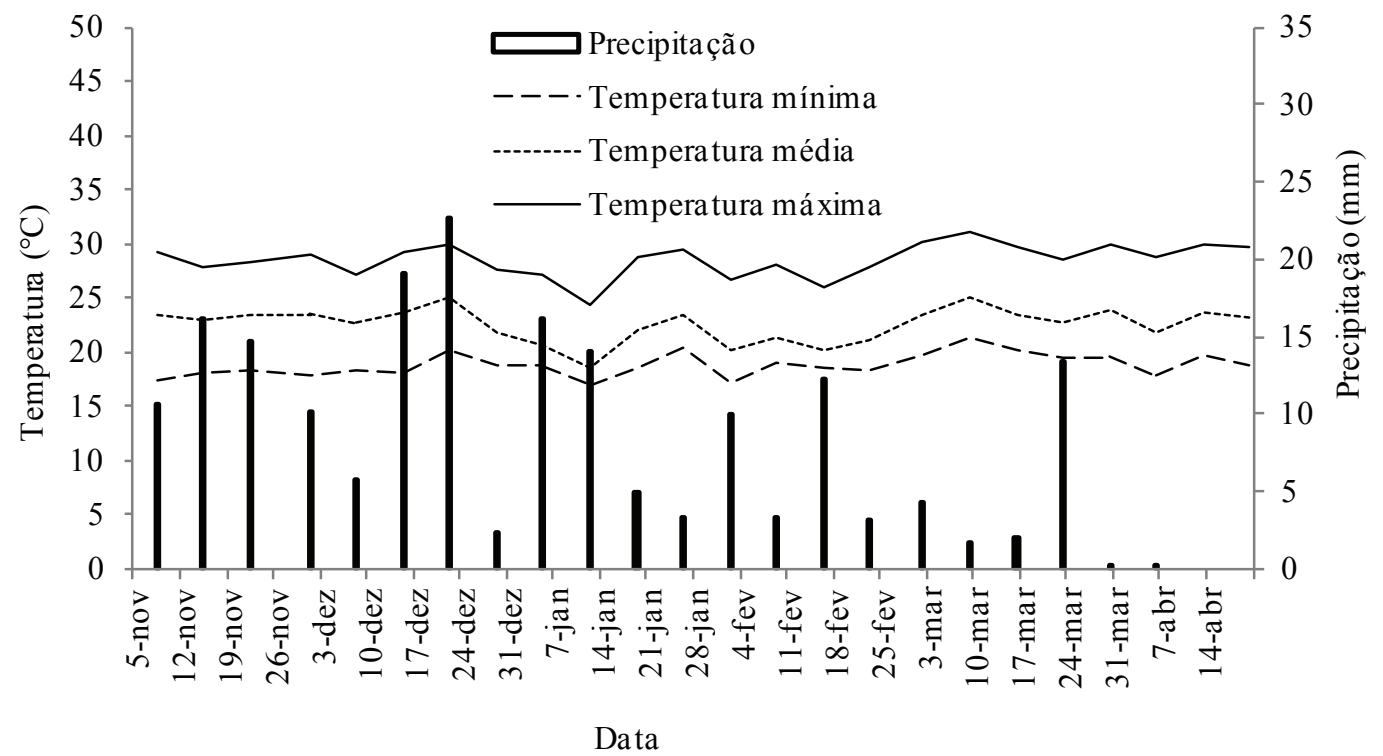

Figura 1. Precipitação e temperaturas máximas, mínimas e médias, obtidas de novembro de 2005 a abril de 2006 (Botucatu, SP).

intermediário e a terceira do moderno (Santos et al. 2006). Cada unidade experimental foi constituída por 8 fileiras de plantas, com $6,0 \mathrm{~m}$ de comprimento, espaçadas em $0,30 \mathrm{~m}$. As 6 fileiras centrais foram consideradas área útil, sendo que $0,50 \mathrm{~m}$ da extremidade de cada fileira de plantas e as duas fileiras externas constituíram-se de bordadura.

A correção do solo foi realizada cerca de 3 meses antes da semeadura, aplicando-se 4,2 $\mathrm{tha}^{-1} \mathrm{de}$ calcário dolomítico de PRNT 90\%, sendo metade da dose aplicada antes da aração e o restante após esta operação, objetivando-se elevar a saturação por bases para 50\% (Raij et al. 1996).

O preparo do solo da área experimental incluiu uma aração e duas gradagens, sendo a primeira realizada logo após a aração e a segunda às vésperas da semeadura. A semeadura foi efetuada no dia 17/11/2005, em espaçamento de $0,30 \mathrm{~m}$ entre as linhas, utilizando-se 240 sementes viáveis $\mathrm{m}^{-2}$. A emergência das plântulas ocorreu aos sete dias após a semeadura. A adubação de semeadura consistiu da aplicação de $20 \mathrm{~kg} \mathrm{ha}^{-1}$ de $\mathrm{N}$ (fonte ureia), $120 \mathrm{~kg} \mathrm{ha}^{-1}$ de $\mathrm{P}_{2} \mathrm{O}_{5}$ (fonte superfosfato simples) e $20 \mathrm{~kg} \mathrm{ha}^{-1} \mathrm{de}$ $\mathrm{K}_{2} \mathrm{O}$ (fonte cloreto de potássio) nos sulcos.

A irrigação do experimento foi realizada por sistema de aspersão convencional, composto por duas linhas laterais e aspersores com vazão de $1,07 \mathrm{~m}^{3}$ hora $^{-1}$. O momento da irrigação foi definido por conjunto de três tensiômetros distribuídos na área e instalados à profundidade de $15,0 \mathrm{~cm}$ (extremidade da cápsula porosa), sendo efetuada a irrigação toda vez que a tensão de água no solo atingia $35,5 \mathrm{kPa}$, elevando-se o teor de água à capacidade de campo (180 $\mathrm{g} \mathrm{kg}^{-1}$ de água).

O controle de plantas daninhas, insetos-praga e doenças foi realizado de acordo com as necessidades da cultura. A adubação de cobertura consistiu da aplicação de $80 \mathrm{~kg} \mathrm{ha}^{-1}$ de $\mathrm{N}$, na forma de ureia, parcelada em três vezes $\left(20 \mathrm{~kg} \mathrm{ha}^{-1}, 30 \mathrm{~kg} \mathrm{ha}^{-1}\right.$ e $\left.30 \mathrm{~kg} \mathrm{ha}^{-1}\right)$, respectivamente aos 13 (pré-perfilhamento), 32 (perfilhamento pleno) e 57 (pré-florescimento) dias após a emergência.

Em função do ciclo das cultivares, foram feitas amostragens aos $39,46,55,67,75,83,92,102,111$, 118 e 125 dias após a emergência (DAE), para as cultivares Caiapó e Maravilha, e aos 39, 46, 55, 67, $75,83,92,102$ e 111 DAE, para a BRS Primavera. Em cada parcela, foram coletadas as plantas contidas em 0,40 m de linha da área útil.

Nas plantas coletadas, foram contados os perfilhos (perfilhos amostra ${ }^{-1}$ ), descartadas as raízes e separadas as folhas verdes e colmos. Em seguida, executou-se a leitura da área foliar do limbo (lâmina foliar), com o auxílio de medidor de área foliar modelo AAM-7, fabricado por Hayashi - Denkoh CO, mediante amostragem de 20 folhas, sendo medida a matéria seca das mesmas e, por comparação com a matéria seca total das folhas, foi encontrada a área foliar total. As partes da planta foram separadas em limbo (lâmina foliar), colmo + bainha e panícula. A 
matéria seca de cada órgão foi obtida quando este foi submetido à secagem a $60^{\circ} \mathrm{C}$, em estufa com circulação forçada de ar, até atingir massa constante. Foram, ainda, estimados o índice de área foliar (IAF) $\left(\mathrm{m}^{2}\right.$ de folhas $\mathrm{m}^{-2}$ de terreno) e a massa seca das folhas verdes e total (colmos + folhas + panícula), segundo equações descritas por Portes et al. (2000).

O IAF foi estimado de acordo com a equação $\mathrm{IAF}=\left[\mathrm{NP} \mathrm{m}^{-1} \mathrm{xAF}\right.$ amostra $] \times$ [espaçamento $\mathrm{x}$ perfilho amostra $\left.{ }^{-1} \times 10.000\right]^{-1}$, sendo que a AF da amostra $\left(\mathrm{cm}^{2}\right)$ e as massas secas das folhas verdes (MSFV) e total (MST) foram estimadas utilizando-se a equação MSFV $($ ou MST $)=\left(\mathrm{NP} \mathrm{m}^{-1} \times \mathrm{MS}\right.$ amostra $) \times($ espaçamento x perfilho amostra $\left.{ }^{-1}\right)$.

O índice de área foliar (IAF), taxa de crescimento da cultura (TCC), taxa de crescimento relativo (TCR), taxa assimilatória líquida ou aparente (TAL) e área foliar específica (AFE) foram estimados com a utilização do programa computacional Anacres (Portes \& Castro Júnior 1991).

O índice fisiológico utilizado para avaliar possíveis diferenças entre as cultivares, segundo Lucchesi (1984), foi a taxa de produção de matéria seca (TPMS), obtida pela manipulação das funções de ajuste, que avalia o crescimento do vegetal, relacionando a quantidade de matéria seca acumulada, em função da área de solo, por unidade de tempo, segundo a equação TPMS $=(\mathrm{M} 2-\mathrm{M} 1) / \mathrm{S} /(\mathrm{t} 2-\mathrm{t} 1)$, sendo TPMS a taxa de produção de matéria seca $\left(\mathrm{kg} \mathrm{ha}^{-1} \mathrm{dia}^{-1}\right)$, M2 e M1 o crescimento em massa de matéria seca, nos tempos t1 e t2 (função da época de coleta das amostras), respectivamente, e $\mathrm{S}$ a área de solo.

Antecedendo a colheita, foi realizada a contagem do número de panículas contidas em 2,0 m de fileiras de plantas, na área útil das parcelas, o qual foi, posteriormente, calculado por metro quadrado. O número de espiguetas por panícula foi obtido por meio da contagem do número de espiguetas de 20 panículas por unidade experimental, coletadas ao acaso, no momento da avaliação do número de panículas por metro quadrado. A fertilidade de espiguetas foi determinada para cada unidade experimental, a partir da relação entre o número de espiguetas granadas por panícula e o número total de espiguetas por panícula, multiplicado por 100 .

A colheita do arroz foi efetuada manualmente e individualmente, por unidade experimental, quando os grãos dos $2 / 3$ superiores de $50 \%$ das panículas apresentaram-se duros e os do terço inferior semiduros.
Foi realizada trilha e secagem à sombra e a limpeza do material, separando-se a palha e as espiguetas chochas, com o auxílio de uma peneira, por meio de abanação manual. Em seguida, determinou-se a massa dos grãos colhidos e calculou-se a produtividade de grãos por hectare $\left(\mathrm{kg} \mathrm{ha}^{-1}\right)(13 \%$ base úmida). Os dados referentes aos componentes de produção e produtividade de grãos foram submetidos à análise de variância e as médias das três cultivares comparadas pelo teste Tukey $(\mathrm{p}<0,05)$, utilizando-se o pacote estatístico Sisvar (Ferreira 1999).

\section{RESULTADOS E DISCUSSÃO}

Constatou-se que, independentemente da cultivar, a curva que melhor ajustou-se aos dados de acúmulo de massa seca total da planta de arroz foi a sigmoide (Figura 2), concordando com os relatos de Santos \& Costa (1997), que trabalharam com cultivares de sequeiro do grupo tradicional. Até o início do perfilhamento, o acúmulo foi pouco expressivo, intensificando-se, de modo quase linear, até o florescimento, pelo fato de, neste período, ocorrerem grandes modificações na planta, como o perfilhamento, aumento gradual em altura, desenvolvimento radicular e de folhas, alongamento de colmos, formação das ramificações da panícula, formação do número de espiguetas por ramificação e dos órgãos florais e meiose (Taiz \& Zeiger 2009, Fageria et al. 2011). A partir do estádio de florescimento das cultivares, verificou-se tendência assintótica de desenvolvimento.

O acúmulo de matéria seca no colmo + bainha foi superior ao das folhas, a partir do início da fase reprodutiva até o final do ciclo das cultivares (Figura 2). As panículas das cultivares Caiapó (Figura 2a) e Maravilha (Figura 2c) apresentaram valores crescentes de matéria seca a partir do seu surgimento até, praticamente, o final do ciclo, sendo que, para a cultivar Maravilha, a matéria seca da panícula não ultrapassou os valores de massa seca das folhas. Com base nestes resultados, pode-se inferir que, para as cultivares Caiapó e Maravilha, a participação final no acúmulo de matéria seca total foi maior no colmo + bainha, seguidos pelas panículas e, depois, folhas.

Para a cultivar BRS Primavera (Figura 2b), constatou-se, também, que a soma colmo + bainha acumulou maior quantidade de fotoassimilados, em relação às folhas, do início da fase reprodutiva até a emissão da panícula. A partir daí, houve nítida translocação de grande parte dos fotoassimilados do 

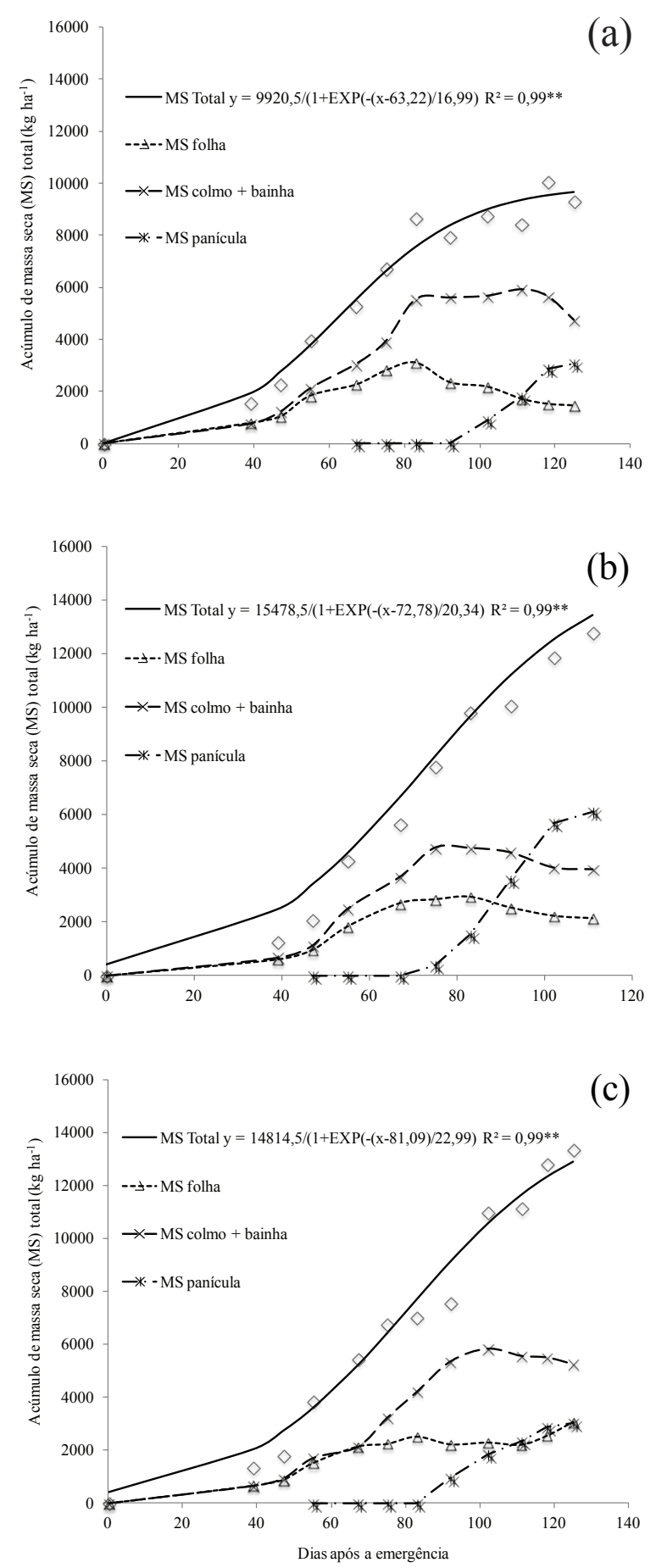

Figura 2. Acúmulo de matéria seca $\left(\mathrm{kg} \mathrm{ha}^{-1}\right)$ de plantas de arroz, ao longo do ciclo das cultivares dos grupos tradicional (a) (Caiapó - fase vegetativa: 0 a 62 dias; fase reprodutiva: 62 a 91 dias; fase de maturação: 91 a 127 dias após o semeio), intermediário (b) (BRS Primavera fase vegetativa: 0 a 43 dias; fase reprodutiva 43 a 74 dias; fase de maturação: 74 a 110 dias após o semeio) e moderno (c) (Maravilha - fase vegetativa: 0 a 63 dias; fase reprodutiva: 63 a 91 dias; fase de maturação: 91 a 124 dias após o semeio) (Botucatu, SP, safra 2005/2006). ** Significativo a $1 \%$, pelo teste F. colmo, bainha e folhas para a formação da panícula, que, a partir dos 98 dias após emergência (DAE), apresentou valores de massa seca superiores aos do colmo + bainha e folhas. No final do ciclo, a participação da panícula na matéria seca total foi a maior, dentre as estruturas avaliadas.

Com relação à taxa de produção de matéria seca (TPMS), verificou-se que foi baixa, no início do ciclo, aumentou rapidamente, até atingir um valor máximo, para, em seguida, decrescer (Figura 3a). Para a cultivar Caiapó, a TPMS máxima foi de $18,8 \mathrm{~g} \mathrm{~m}^{-2} \mathrm{dia}^{-1}$ e a média de $10,8 \mathrm{~g} \mathrm{~m}^{-2} \mathrm{dia}^{-1}$; para a BRS Primavera, a máxima foi de $18 \mathrm{~g} \mathrm{~m}^{-2} \mathrm{dia}^{-1}$ e a média de $14,0 \mathrm{~g} \mathrm{~m}^{-2} \mathrm{dia}^{-1}$; e, para a Maravilha, a máxima foi de $16,0 \mathrm{~g} \mathrm{~m}^{-2} \mathrm{dia}^{-1}$ e a média de $11,6 \mathrm{~g} \mathrm{~m}^{-2} \mathrm{dia}^{-1}$.

A TPMS é um parâmetro importante, porque demonstra o incremento de matéria seca por unidade de área e por unidade de tempo, sendo classificada como produtividade primária líquida (Lucchesi 1984, Bortolini et al. 2002, Costa et al. 2008). Assim, a cultivar do grupo tradicional (Caiapó), como era esperado, apresentou maior crescimento, e a cultivar Maravilha (grupo moderno), também como esperado, apresentou o menor crescimento.

Para o índice de área foliar, observou-se que, dos 39 DAE aos 47 DAE, houve tendência similar entre as cultivares BRS Primavera e Maravilha (Figura 3b). Dos 55 DAE aos 90 DAE, a BRS Primavera apresentou maiores valores de IAF, quando comparados aos da Maravilha. Em seguida, os valores de IAF começaram a diminuir, devido ao aumento na quantidade de folhas senescentes. Os valores de IAF, para a cultivar Caiapó, foram maiores, dos $39 \mathrm{DAE}$ aos $102 \mathrm{DAE}$, se comparados às demais cultivares. A partir dos 102 DAE, estes valores foram superados pela cultivar Maravilha, que manteve este patamar até o final do ciclo.

As cultivares Caiapó e BRS Primavera alcançaram, aos 83 DAE, o IAF máximo de $5,8 \mathrm{~m}^{2}$ e $4,3 \mathrm{~m}^{2}$ de folhas por $\mathrm{m}^{-2}$ de terreno, respectivamente. Já a cultivar Maravilha explorou o máximo espaço disponível por volta dos $92 \mathrm{DAE}\left(4,2 \mathrm{~m}^{2}\right.$ de folhas por $\mathrm{m}^{-2}$ de terreno). Depois de alcançado o IAF máximo, observou-se diminuição destes valores, para todas as cultivares, atingindo valores próximos a 1, na cultivar Caiapó. A redução do IAF, no final do ciclo, deve-se à redução da área foliar útil, com a senescência da planta, morte e queda de folhas (Pinheiro et al. 1985, Campos et al. 2008). 

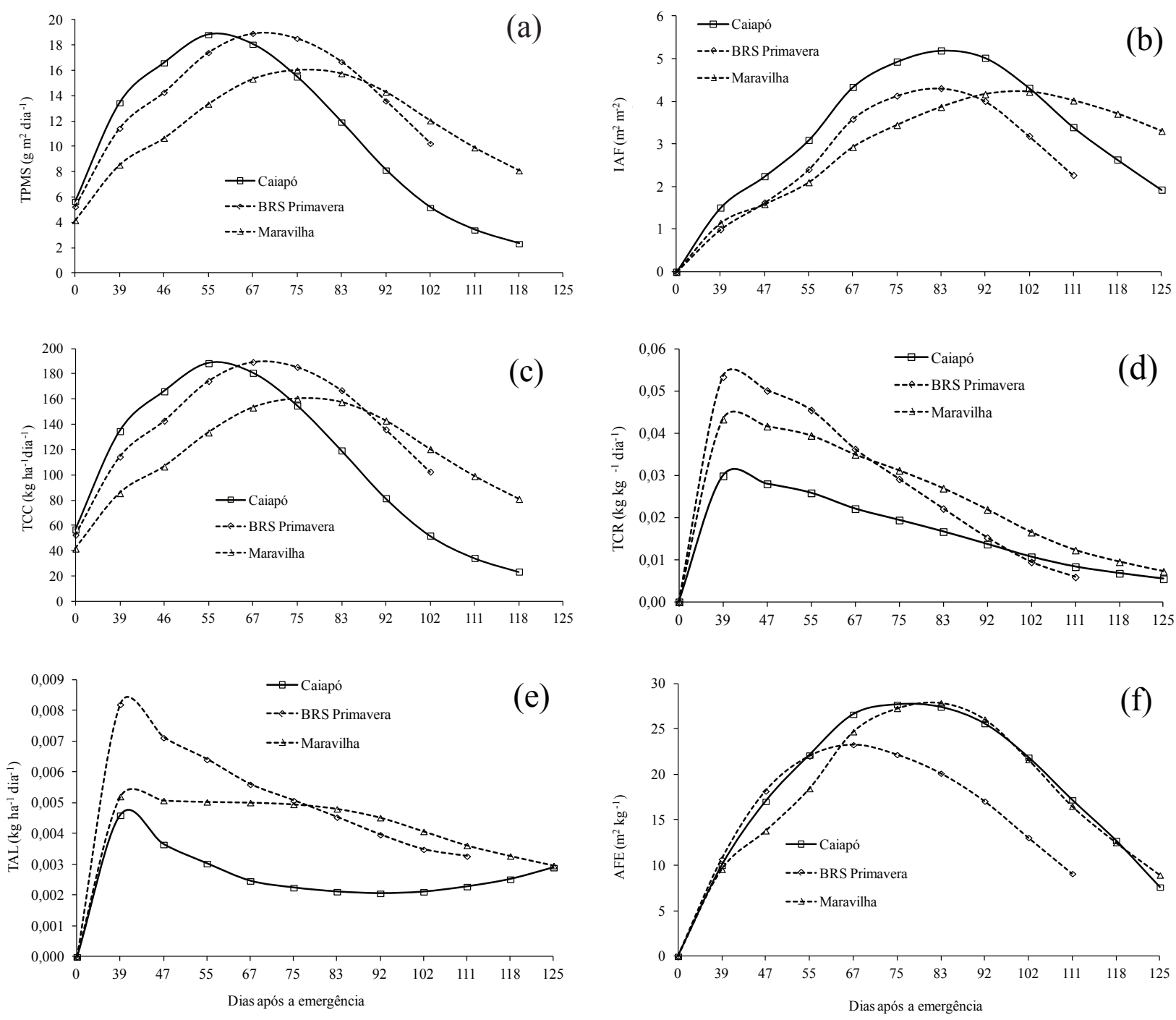

Figura 3. Taxa de produção de matéria seca da parte aérea (TPMS) $\left(\mathrm{g} \mathrm{m}^{2} \mathrm{dia}^{-1}\right)(\mathrm{a})$, índice de área foliar (IAF) $\left(\mathrm{m}^{2} \mathrm{de}\right.$ folhas $\mathrm{m}^{-2}$ de terreno) (b), taxa de crescimento da cultura (TCC) $\left(\mathrm{kg} \mathrm{ha}^{-1} \mathrm{dia}^{-1}\right)(\mathrm{c})$, taxa de crescimento relativo (TCR) $\left(\mathrm{kg} \mathrm{kg}^{-1} \mathrm{dia}^{-1}\right)$ (d), taxa assimilatória líquida (TAL) $\left(\mathrm{kg} \mathrm{ha}^{-1} \mathrm{dia}^{-1}\right)(\mathrm{e})$ e área foliar específica (AFE) $\left(\mathrm{m}^{2} \mathrm{~kg}^{-1}\right)$ (f) das cultivares dos grupos tradicional (Caiapó), intermediário (BRS Primavera) e moderno (Maravilha) (Botucatu, SP, safra 2005/2006).

Segundo Santos \& Costa (1997), a produtividade de grãos, normalmente, aumenta com o IAF, quando não ocorre limitação de água no solo. Em condições de deficiência hídrica, pode haver redução na produtividade de grãos de arroz (Crusciol et al. 2006). No entanto, valores baixos de $\operatorname{IAF}(<2,0)$ ajudam a minimizar perdas por deficiência hídrica, mas reduzem o potencial produtivo do arroz (Campos et al. 2008).

Houve tendência semelhante entre as cultivares, com o aumento da TCC, à medida em que a cultura se desenvolveu, alcançando valores máximos, para, depois, decrescer (Figura 3c), à semelhança do observado para índice de área foliar e como reflexo deste (Santos \& Costa 1997, Campos et al. 2008, Taiz \& Zeiger 2009).

O IAF ótimo é alcançado quando a taxa de crescimento da cultura (TCC) é máxima (Santos \& Costa 1997). De acordo com esta definição, o IAF ótimo, para as cultivares Caiapó e BRS Primavera, foi alcançado aos 55 DAE e 67 DAE, respectivamente, na fase reprodutiva, quando a TCC foi máxima $\left(188,36 \mathrm{~kg} \mathrm{ha}^{-1} \mathrm{dia}^{-1}\right.$ e $189,28 \mathrm{~kg} \mathrm{ha}^{-1} \mathrm{dia}^{-1}$, respectivamente). Para a cultivar Maravilha, o IAF ótimo foi alcançado aos 75 DAE, também na fase reprodutiva, quando a TCC foi máxima (160,36 $\left.\mathrm{kg} \mathrm{ha}^{-1} \mathrm{dia}^{-1}\right)$.

De acordo com Rossetto \& Nakagawa (2001), os valores máximos de TCC, geralmente, coincidem 
com os primeiros estádios de frutificação, seguindo-se de decréscimo, com a maturação das plantas, devido à paralização do crescimento vegetativo, perda de folhas e senescência. Os maiores valores de TCC foram obtidos pela cultivar BRS Primavera, apesar de não ter apresentado o maior IAF, indicando que esta cultivar foi mais eficiente fotossinteticamente, quando comparada à cultivar Caiapó, que apresentou maior IAF, o que pode estar associado a características da própria planta, onde a primeira cultivar pertence ao grupo intermediário, com plantas de porte médio e folhas menos decumbentes, em relação às plantas da Caiapó, pertencente ao grupo tradicional, de porte alto, folhas decumbentes e crescimento exuberante.

A TCR reflete o aumento da matéria seca da planta, ou qualquer órgão desta, num intervalo de tempo, sendo função do tamanho inicial, ou seja, do material pré-existente, havendo tendência de diminuição da TCR, com a idade da planta (Bortolini et al. 2002, Ntanos \& Koutroubas 2002, Falqueto et al. 2009). Assim, verificou-se que houve redução constante da TCR, com o avanço dos DAE (Figura 3d), em função de a planta se encontrar em fase de senescência, com queda e morte de folhas. Esta redução, geralmente, está associada ao acúmulo de matéria seca, durante o desenvolvimento, e à queda na habilidade relativa de as plantas produzirem nova biomassa (Antoniazzi \& Deschamps 2006, Falqueto et al. 2009). Além disto, este decréscimo da TCR, com a idade da planta, em parte, é resultado do aumento gradativo de tecidos não assimilatórios (Pinheiro et al. 1985, Taiz \& Zeiger 2009). Neste trabalho, os decréscimo da TCR foram maiores para a cultivar BRS Primavera, com maior produção de massa seca (Figura 3) e menor ciclo cultural.

A taxa assimilatória líquida (TAL) reflete a eficiência do sistema assimilador envolvido na produção de massa seca, estimando a fotossíntese líquida (Santos \& Costa 1997, Falqueto et al. 2009). No início, os valores da TAL foram altos, refletindo em elevada capacidade de as folhas jovens realizarem fotossíntese, conforme descrito por Antoniazzi \& Deschamps (2006). Posteriormente, os valores foram diminuindo, com o avanço dos DAE, como observado para TCC e TCR, em função de as plantas encontrarem-se em fase de senescência, com queda e morte das folhas, conforme observado por Alvarez et al. (2005), em amendoim; Antoniazzi \& Deschamps (2006), em cevada; e Ntanos \& Koutroubas (2002) e Falqueto et al. (2009), em arroz.
Dos 39 DAE aos 75 DAE, observou-se que a cultivar BRS Primavera (Figura 3e) apresentou maior valor de TAL, em relação às demais cultivares que apresentaram valores próximos e menores que este, indicando maior eficiência do sistema assimilador (Fageria 2007).

Na literatura, existe certa controvérsia entre os estudos sobre TAL (Santos et al. 2006). Alguns autores reportam aumentos de TAL até uma determinada idade da planta, enquanto, para outros, não há variações durante o desenvolvimento da planta da mesma espécie (Falqueto et al. 2009). Tais divergências, talvez, sejam devidas à influência de condições climáticas, forma de condução dos experimentos e variações intraespecíficas desta taxa, assim como da espécie de planta estudada e locais em que foram desenvolvidos os experimentos, sendo que alguns poderiam apresentar microclima mais favorável que outros (Rosetto \& Nakagawa 2001).

Constatou-se que houve aumento de AFE para a cultivar BRS Primavera, dos 39 DAE até 67 DAE (Figura 3f), como decorrência da alteração morfológica nas folhas, por meio do aumento na expansão foliar. Para as cultivares Caiapó e Maravilha, houve a mesma tendência, com maiores valores aos $83 \mathrm{DAE}$, entretando, não foram constatadas grandes alterações entre estas cultivares, para este índice, ao longo do ciclo.

Segundo Taiz \& Zeiger (2009), a AFE representa as diferenças no espessamento foliar, ou seja, permite verificar se as plantas estão acumulando fotoassimilados em suas folhas ou se estão translocando para outros órgãos. Para a cultivar BRS Primavera, os valores de AFE tenderam a diminuir, de maneira acentuada, a partir de $75 \mathrm{DAE}$, até $102 \mathrm{DAE}$, indicando diminuição da AF e/ou acúmulo de fotossintetizados nas folhas, correspondendo, este período, à fase de maturação da planta, com grãos em início de formação (Falqueto et al. 2009).

O número de panículas não foi diferente entre as cultivares (Tabela 1), apesar de estas possuírem características distintas, quanto à capacidade de perfilhamento, tendo a Caiapó e a BRS Primavera média capacidade e a Maravilha alta capacidade de perfilhamento (Santos et al. 2006), visto que o número de panículas por metro quadrado depende, dentre outros, do número de colmos por metro quadrado (Fageria 2007, Fageria et al. 2011).

O número de espiguetas por panícula foi maior para a cultivar BRS Primavera, diferindo, significativamente, das demais. Estas diferenças, provavel- 
Tabela 1. Componentes da produção e produtividade de grãos $\left(\mathrm{kg} \mathrm{ha}^{-1}\right)$ das cultivares de arroz Caiapó, BRS Primavera e Maravilha, cultivadas em condições de terras altas, favorecidas com o uso de irrigação suplementar (Botucatu, SP, safra 2005/2006).

\begin{tabular}{lccccc}
\hline \multirow{2}{*}{ Cultivares } & Panículas $\mathrm{m}^{-2}$ & $\begin{array}{c}\text { Espiguetas } \\
\text { panícula }\end{array}$ & $\begin{array}{c}\text { Fertilidade de } \\
\text { espiguetas }\end{array}$ & $\begin{array}{c}\text { Massa de } 1.000 \\
\text { grãos }\end{array}$ & Produtividade \\
\cline { 2 - 6 } & número & número & $\%$ & $\mathrm{~g}$ & $\mathrm{~kg} \mathrm{ha}^{-1}$ \\
\hline Caiapó & 241 & $114 \mathrm{~b}$ & 76,5 & $27,0 \mathrm{a}$ & $4.157 \mathrm{~b}$ \\
BRS Primavera & 253 & $151 \mathrm{a}$ & 76,1 & $24,7 \mathrm{ab}$ & $6.010 \mathrm{a}$ \\
Maravilha & 260 & $92 \mathrm{~b}$ & 77,4 & $22,3 \mathrm{~b}$ & $4.094 \mathrm{~b}$ \\
\hline Cultivar & $0,73^{\text {ns }}$ & $23,30^{* *}$ & $0,08^{\text {ns }}$ & $9,96^{* *}$ & $5,24^{*}$ \\
C.V. $(\%)$ & 11,91 & 13,69 & 7,52 & 7,89 & 26,47 \\
\hline
\end{tabular}

Médias seguidas da mesma letra, na coluna, não diferem entre si, pelo teste Tukey, a $5 \%$. * ** e ns: Significativo a $5 \%, 1 \%$ e não significativo, respectivamente.

mente, são intrínsecas às cultivares, ou seja, estão diretamente relacionadas às características genéticas dos materiais, uma vez que, durante a formação das panículas (fase reprodutiva), as condições climáticas do experimento foram as mesmas para as três cultivares, além de estarem dentro da faixa adequada para a cultura do arroz (Pinheiro et al. 1985, Fageria 2007, Santos et al. 2006).

Quanto à fertilidade das espiguetas, não houve diferença significativa entre as cultivares, o que atesta a adequada disponibilidade hídrica, durante a condução do experimento, bem como as temperaturas máximas $\left(30^{\circ} \mathrm{C}\right)$ e mínimas $\left(20^{\circ} \mathrm{C}\right)$ dentro dos limites, para o desenvolvimento satisfatório da cultura (Figura 1), pois, sob condições de deficiência hídrica, ou elevadas temperaturas, a fertilidade das espiguetas é significativamente reduzida (Santos et al. 2006, Fageria 2007, Fageria et al. 2011).

Com relação à produtividade de grãos, os maiores resultados foram obtidos com a cultivar BRS Primavera $\left(6.010 \mathrm{~kg} \mathrm{ha}^{-1}\right)$, diferindo, estatisticamente, das cultivares Maravilha (4.094 $\mathrm{kg} \mathrm{ha}^{-1}$ ) e Caiapó (4.157 $\left.\mathrm{kg} \mathrm{ha}^{-1}\right)$, e o componente de produção que mais afetou esta diferença foi o número de espiguetas por panícula, seguido da massa de 1.000 grãos (Tabela 1).

Além disso, observou-se que a cultivar mais produtiva (BRS Primavera do grupo intermediário) apresentou a maior massa de matéria seca das panículas e, também, a maior matéria seca total (Figura 3b), o que influenciou, positivamente, na produtividade de grãos, corroborando as informações de vários autores (Santos \& Costa 1997, Antoniazzi \& Deschamps 2006, Campos et al. 2008, Costa et al. 2008, Fageria et al. 2011) que afirmaram que a produção de matéria seca se relaciona estreitamente com a produtividade de grãos, na cultura do arroz.

Com relação ao IAF, constatou-se que a cultivar Caiapó (menos produtiva) apresentou valores maiores, se comparada às demais cultivares, de 39 DAE a 102 DAE, e, a partir dos 102 DAE, estes valores foram superados pela cultivar Maravilha (também menos produtiva), mantendo este patamar até o final do ciclo.

Segundo Santos \& Costa (1997), na ausência de deficiência hídrica, um alto IAF não é garantia de alta produtividade, principalmente quando associado à alta pluviosidade e nebulosidade, no período reprodutivo. Além disto, altos IAFs podem significar autosombreamento e redução na taxa fotossintética média por unidade de área foliar (Campos et al. 2008).

A cultivar BRS Primavera também apresentou os maiores valores de TCC (Figura 3c), apesar de não ter apresentado o maior IAF (Figura 3b), indicando que esta cultivar foi mais eficiente fotossinteticamente, o que se traduziu na maior produtividade (Tabela 1). A TCR apresentou decréscimo, com a idade da planta, devido ao aumento gradativo de tecidos não assimilatórios (Taiz \& Zeiger 2009), e foi mais característica na cultivar BRS Primavera, que apresentou maior produção de massa seca (Figura 2b) e menor ciclo, o que, também, pode explicar a maior produtividade de grãos obtida com esta cultivar (Tabela 1).

Outro parâmetro que se destacou, na cultivar BRS Primavera, foi a taxa de assimilação líquida (TAL), sendo constatado, dos 39 DAE aos 67 DAE, o maior valor, em comparação às outras cultivares, que apresentaram valores próximos e inferiores a este, indicando maior eficiência do sistema assimilador da cultivar BRS Primavera, com reflexos na produtividade de grãos.

\section{CONCLUSÕES}

1. As cultivares dos grupos intermediário (BRS Primavera) e tradicional (Caiapó) obtiveram os maiores acúmulos de matéria seca total. 
2. As cultivares dos grupos tradicional (Caiapó) e moderno (Maravilha) apresentaram os maiores índices de área foliar.

3. A cultivar do grupo intermediário (BRS Primavera) apresentou os maiores índices de taxa de crescimento da cultura, taxa de crescimento relativo, taxa assimilatória líquida e área foliar específica, bem como a maior produtividade de grãos, em decorrência dos maiores valores de fertilidade das espiguetas e da massa de 1.000 grãos.

\section{AGRADECIMENTOS}

À Fundação de Amparo à Pesquisa do Estado de São Paulo (FAPESP), pelo financiamento da pesquisa, e ao Conselho Nacional de Desenvolvimento Científico e Tecnológico (CNPq), pela concessão de bolsa de produtividade em pesquisa ao segundo autor.

\section{REFERÊNCIAS}

ALVAREZ, R. de C. F. et al. Análise de crescimento de duas cultivares de amendoim (Arachishypogaea L.). Acta Scientiarum Agronomy, Maringá, v. 27, n. 4, p. 611-616, 2005.

ANTONIAZZI, N.; DESCHAMPS, C. Análise de crescimento de duas cultivares de cevada após tratamentos com elicitores e fungicidas. Ciência Rural, Santa Maria, v. 36, n. 4, p. 1065-1071, 2006.

BENICASA, M. M. P. Análise de crescimento de plantas: noções básicas. 2. ed. Jaboticabal: Funep, 2003.

BORTOLINI, C. G. et al. Sistemas de aplicação de nitrogênio e seus efeitos sobre o acúmulo de $\mathrm{N}$ na planta de milho. Revista Brasileira de Ciência do Solo, Viçosa, v. 26, n. 2, p. 373-380, 2002.

CAMPOS, M. F. de et al. Análise de crescimento em plantas de soja tratadas com substâncias reguladoras. Revista Biotemas, Botucatu, v. 21, n. 3, p. 53-63, 2008.

COMPANHIA NACIONAL DE ABASTECIMENTO (Conab). Levantamento da produção de grãos: safra 2011/2012. Disponível em: <www.conab.gov.br>. Acesso em: 25 ago. 2012.

CONCENÇO, G. I. et al. Photosynthetic characteristics of hybrid and conventional rice plants as a function of plant competition. Planta Daninha, Viçosa, v. 29, n. 4, p. 803-809, 2011.

COSTA, J. R. da et al. Produção de matéria seca de cultivares de milho sob diferentes níveis de estresse hídrico. Revista Brasileira de Engenharia Agrícola e Ambiental, Campina Grande, v. 12, n. 5, p. 443-450, 2008.
CRUSCIOL, C. A. C. et al. Yield of upland rice cultivars in rainfed and sprinkler-irrigated systems in the Cerrado region of Brazil. Australian Journal of Experimental Agriculture, Collingwood, v. 46, n. 11, p. 1515-1520, 2006.

EMPRESA BRASILEIRA DE PESQUISA AGROPECUÁRIA (Embrapa). Centro Nacional de Pesquisa de Solos. Sistema brasileiro de classificação de solos. Brasília, DF: Embrapa Produção de Informação; Rio de Janeiro: Embrapa Solos, 2006.

FAGERIA, N. K. Yield physiology of rice. Journal of Plant Nutrition, Athens, v. 30, n. 6, p. 843-879, 2007.

FAGERIA, N. K. et al. Yield and yield components of upland rice as influenced by nitrogen sources. Journal of Plant Nutrition, Athens, v. 34, n. 3, p. 361-370, 2011.

FALQUETO, A. R. et al. Partição de assimilados em cultivares de arroz diferindo no potencial de produtividade de grãos. Bragantia, Campinas, v. 68 , n. 3, p. 453-461, 2009.

FERREIRA, D. F. Sisvar: sistema de análise de variância. Lavras: UFLa, 1999.

FOOD AND AGRICULTURE ORGANIZATION OF THE UNITED NATIONS (FAO). Productions indices. 2012. Disponível em: <http://faostat.fao.org/site/567/ DesktopDefault.aspx?PageID=567\#ancor $>$. Acesso em: 25 ago. 2012.

GUIMARÃES, C. M. et al. Sistema radicular do arroz de terras altas sob deficiência hídrica. Pesquisa Agropecuária Tropical, Goiânia, v. 41, n. 1, p. 126-134, 2011.

HEINEMANN, A. B.; STONE, L. F. Efeito da deficiência hídrica no desenvolvimento e rendimento de quatro cultivares de arroz de terras altas. Pesquisa Agropecuária Tropical, Goiânia, v. 39, n. 2, p. 134-139, 2009.

KATO, M. et al. Photosynthesis and dry-matter production during ripening stage in a female-sterile line of rice. Plant Production Science, Tokyo, v. 7, n. 2, p. 184-188, 2004.

LUCCHESI. A. A. Utilização prática da análise de crescimento vegetal. Anais da Escola Superior de Agricultura "Luiz de Queiroz", Piracicaba, v. 41, n. 1, p. 181-202, 1984.

MENEZES, B. R. S. et al. Caracterização morfoagronômica em arroz vermelho e arroz de sequeiro. Pesquisa Agropecuária Tropical, Goiânia, v. 41, n. 4, p. 490-499, 2011.

NASCENTE, A. S. et al. Produtividade do arroz de terras altas em função do manejo do solo e da época de aplicação de nitrogênio. Pesquisa Agropecuaria Tropical, Goiânia, v. 41, n. 1, p. 60-65, 2011.

NTANOS, D. A.; KOUTROUBAS, S. D. Dry matter and $\mathrm{N}$ accumulation and translocation for Indica and 
Japonica rice under Mediterranean conditions. Field Crops Research, New York, v. 74, n. 1, p. 93-101, 2002.

PINHEIRO, B. S. et al. Tipo de planta, regime hídrico e produtividade do arroz de sequeiro. Pesquisa Agropecuária Brasileira, Brasília, DF, v. 20, n. 1, p. 85-87, 1985.

PORTES, T. A. et al. Análise do crescimento de uma cultivar de braquiária em cultivo solteiro e consorciado com cereais. Pesquisa Agropecuaria Brasileira, Brasília, DF, v. 35, n. 7, p. 1349-1358, 2000.

PORTES, T. A.; CASTRO JÚNIOR, L. G. Análise de crescimento de plantas: um programa computacional auxiliar. Revista Brasileira de Fisiologia Vegetal, Campinas, v. 3, n. 1, p. 53-56, 1991.

RAIJ, B. V. et al. Recomendações de adubação e calagem para o Estado de São Paulo. 2. ed. Campinas: Instituto Agronômico, 1996.
ROSSETTO, C.; NAKAGAWA, J. Época de colheita e desenvolvimento vegetativo de aveia preta. Scientia Agricola, Piracicaba, v. 58, n. 4, p. 731-736, 2001.

SANTOS, A. B. dos; COSTA, J. D. Crescimento de arroz de sequeiro em diferentes populações e irrigação suplementar. Pesquisa Agropecuária Brasileira, Brasília, DF, v. 32, n. 10, p. 591-599, 1997.

SANTOS, A. B. et al. A cultura do arroz no Brasil. 2. ed. Santo Antônio de Goiás: Embrapa Arroz e Feijão, 2006.

STONE, L. F.; STEINMETZ, S. Índice de área foliar e adubação nitrogenada em arroz. Pesquisa Agropecuária Brasileira, Brasília, DF, v. 14, n. 1, p. 25-28, 1979.

TAIZ, L.; ZEIGER, E. Fisiologia vegetal. 4. ed. Porto Alegre: Artmed, 2009. 